\title{
Pulsed High-Intensity Focused Ultrasound Enhances Uptake of Radiolabeled Monoclonal Antibody to Human Epidermoid Tumor in Nude Mice
}

\author{
Alfia Khaibullina*1, Beom-Su Jang*2, Haihao Sun ${ }^{1}$, Nhat $\mathrm{Le}^{2}$, Sarah $\mathrm{Yu}^{2}$, Victor Frenkel ${ }^{1}$, Jorge A. Carrasquillo ${ }^{2}$, \\ Ira Pastan ${ }^{3}$, King C.P. $\mathrm{Li}^{1}$, and Chang H. Paik ${ }^{2}$ \\ ${ }^{1}$ Department of Radiology, Clinical Center, National Institutes of Health, Bethesda, Maryland; ${ }^{2}$ Department of Nuclear Medicine, \\ Clinical Center, National Institutes of Health, Bethesda, Maryland; and ${ }^{3}$ Laboratory of Molecular Biology, National Cancer Institute, \\ National Institutes of Health, Bethesda, Maryland
}

The aim of this study was to determine if pulsed high-intensity focused ultrasound (HIFU) exposures could enhance tumor uptake of ${ }^{111} \mathrm{In}-\mathrm{MX}-\mathrm{B} 3$, a murine $\operatorname{lgG} 1 \kappa$ monoclonal antibody directed against the $\mathrm{Le}^{\mathrm{y}}$ antigen. Methods: MX-B3 was labeled with ${ }^{111} \mathrm{In}$, purified, and confirmed for its binding to the antigenpositive A431 cell line. Groups of nude mice were inoculated subcutaneously with A431 tumor cells on both hind flanks. A tumor on one flank was treated with pulsed-HIFU; the other tumor was used as an untreated control. Within 10 min after the HIFU exposure, the mice received intravenous ${ }^{111}$ In-MX-B3 for imaging and biodistribution studies. Mice were euthanized at 1, 24, 48, and $120 \mathrm{~h}$ after injection for biodistribution studies. Results: The HIFU exposure shortened the peak tumor uptake time (24 vs. $48 \mathrm{~h}$ for the control) and increased the peak tumor uptake value (38 vs. $25 \%$ ID/g [percentage injected dose per gram] for the control). The HIFU effect on enhancing tumor uptake was greater at earlier times up to $24 \mathrm{~h}$, but the effect was gradually diminished thereafter. The HIFU effect on enhancing tumor uptake was substantiated by nuclear imaging studies. HIFU also increased the uptake of the antibody in surrounding tissues, but the net increase was marginal compared with the increase in tumor uptake. Conclusion: This study demonstrates that pulsed-HIFU significantly enhances the delivery of ${ }^{111} \mathrm{In}-\mathrm{MX}-\mathrm{B} 3$ in human epidermoid tumors xenografted in nude mice. The results of this pilot study warrant further evaluation of other treatment regimens, such as repeated HIFU exposures for greater delivery enhancement of antibodies labeled with cytotoxic radioisotopes or pulsed-HIFU exposure in addition to a combined therapy of ${ }^{90} \mathrm{Y}-\mathrm{B} 3$ and taxol to enhance the synergistic effect.

\footnotetext{
Received Aug. 31, 2007; revision accepted Oct. 16, 2007.

For correspondence or reprints contact: Chang $\mathrm{H}$. Paik, PhD, Department of Nuclear Medicine, Clinical Center, NIH, Building 21, Room 136, Bethesda, MD 20892.

E-mail: cpaik@mail.nih.gov

${ }^{*}$ Contributed equally to this work.

COPYRIGHT @ 2008 by the Society of Nuclear Medicine, Inc.
}

Key Words: pulsed-HIFU; enhanced tumor uptake; ${ }^{111} \mathrm{In}-\mathrm{MX}-$ B3; A431 tumor

J Nucl Med 2008; 49:295-302

DOI: 10.2967/jnumed.107.046888

M onoclonal antibodies (mAbs) play a prominent role in cancer therapy. They can interact with specific antigens on cancer cells, thereby enhancing the patient's immune response via various mechanisms, or they can act against cell growth factors, thus arresting proliferation of tumor cells $(1,2)$. In the setting of therapy, typically large amounts of antibody are administered over a long period of time to exert a biologic effect $(3,4)$. Although considerable research has been performed evaluating mAbs for therapy, limited success has been achieved with antibody monotherapy. Alternatively, $\mathrm{mAbs}$ have been armed with cytotoxic radioisotopes to potentiate therapeutic effects. Recently, 2 anti-CD20 mAbs armed with ${ }^{90}$ Y-ibritumomab tiuxetan (Zevalin; IDEC Pharmaceuticals) and ${ }^{131}$ I-tositumomab (Bexxar; GlaxoSmithKline) have been approved by the Food and Drug Administration for radioimmunotherapy of hematologic malignancies $(5,6)$. Other mAbs with cytotoxic radioisotopes targeting different antigens in hematologic malignancies have also shown frequent tumor responses $(7,8)$. This contrasts with radiolabeled antibodies targeting solid tumors, which generally have shown little or no evidence of tumor response $(9,10)$.

Various impediments have been described in solid tumors to explain the limited targeting of mAbs, including vascular, stromal, and interstitial barriers $(11,12)$. Furthermore, as a result of tumor binding-site barriers (13), radiolabeled mAbs bind primarily to tumor cells nearest to vasculature, thus preventing homogeneous distribution of radiolabeled antibody throughout the tumor. These barriers often result in limited tumor uptake and heterogeneous distribution. Several 
approaches to overcome these barriers have been investigated, including the use of antibody fragments and pretargeting. Biodistribution studies of radiolabeled fragments have demonstrated that smaller-molecular-weight antibody fragments shorten peak tumor uptake time and increase tumor-toblood radioactivity ratios due to rapid blood clearance and better penetration (14-16). However, radiolabeled fragments generally result in lower peak tumor uptake values, faster washout rates from tumors due to a lower binding affinity to tumor antigens, and high renal uptake. Alternative approaches to improve targeting and decrease radiation exposure to the subject are being pursued using 2- or 3-step pretargeting approaches (17-19). Pretargeting approaches provide opportunities to decouple the antibody injection from the radiolabel injection, thereby enabling amplification of tumor-to-nontumor background ratios. One disadvantage of pretargeting approaches is that they involve sequential injections of multiple components, including an antibody conjugate, a clearance agent, and a radiolabel. These approaches are complex and, in some cases, the reagents are immunogenic.

In an attempt to explore other methods to improve tumor targeting, we turned to the modality of high-intensity focused ultrasound (HIFU). HIFU is predominantly being used for thermal ablation of prostate cancer and is currently under clinical trials for ablation of other types of cancer, including malignancies of the liver and breast, as well as for uterine fibroids (20). Tumor ablation involves relatively long, continuous exposures to HIFU to generate the high temperature elevations necessary (20). In contrast, pulsedHIFU exposures with relatively "low-duty cycles" (low HIFU exposure on/off ratios) generate low levels of heat that are not biologically relevant; instead, various nonthermal mechanisms (e.g., cavitation, radiation forces) come into play. These, in turn, can produce mechanical effects that enhance the permeability of the targeted tissue in a nondestructive manner. In preclinical studies, pulsed-HIFU exposures have been shown to enhance the delivery of various chemotherapeutic agents to tumors-consequently, improving their antitumor effects (21). These exposures, with the addition of ultrasound contrast agents, have also been used to improve the delivery of HER2 antibodies across the blood-brain barrier (22). In this study we wanted to determine if preexposing a solid epidermoid tumor to pulsed-HIFU could increase the targeting of a radiolabeled $\mathrm{mAb}$ in tumor xenografts.

B3 is a murine IgGlк mAb that reacts with a carbohydrate epitope found on the Lewis ${ }^{\mathrm{y}}$ and the polyfucosylated Lewis ${ }^{\mathrm{x}}$ antigens. This epitope is abundantly and uniformly expressed by most carcinomas (23). In preclinical studies, tumor targeting of radiolabeled B3 was investigated in nude mice xenografted with A431, a human epidermoid carcinoma cell line expressing the Lewis ${ }^{\mathrm{y}}(24,25)$. Biodistribution of ${ }^{111} \mathrm{In} /{ }^{88}$ Y-radiolabeled B3 antibody has shown good tumor localization in A431 tumor-bearing nude mice $(24,25)$. This work led to a phase 1 trial with ${ }^{111}$ In- and ${ }^{90} \mathrm{Y}-\mathrm{B} 3$. In this trial, although definite tumor imaging was observed in 20 of 26 patients, no antitumor effect was observed, presumably because of the insufficient dose delivered to tumors before dose-limiting toxicity was reached (10). Thus, in this study, we explored whether pulsed-HIFU could improve the delivery and tumor targeting of B3 in a mouse tumor xenograft system.

\section{MATERIALS AND METHODS}

\section{Conjugation of Bifunctional Chelate to mAb B3}

The isolation and characterization (23) of $\mathrm{mAb} B 3$ and the conjugation of mAb B3 with 2-(p-SCN-Bz)-6-methyl-DTPA ([MX] where DTPA is diethylenetriaminepentaacetic acid) (24) were described previously. The final concentration of MX-B3 conjugate was $10.8 \mathrm{mg} / \mathrm{mL}$. This conjugate was divided into $100-\mu \mathrm{L}$ aliquots that were stored in a freezer at $-80^{\circ} \mathrm{C}$ until needed.

\section{Radiolabeling of mAb B3 with ${ }^{111}$ In}

Radiolabeling with ${ }^{111}$ In was performed using a method reported previously (24). Briefly, 74-111 MBq (2-3 mCi) of ${ }^{111} \mathrm{InCl}_{3}$ (PerkinElmer Inc.; $5 \mathrm{mCi} / 20 \mu \mathrm{L}$ of $0.05 \mathrm{M} \mathrm{HC} 1$ ) were adjusted to $\mathrm{pH} 4.2$ with $100 \mu \mathrm{L}$ of a buffer solution containing $0.2 \mathrm{M}$ sodium acetate and $0.025 \mathrm{M}$ sodium ascorbate in a polypropylene vial. Typically, $20 \mu \mathrm{L}$ of antibody solution $(10.8 \mathrm{mg} / \mathrm{mL}, \mathrm{pH} 7)$ were added and allowed to react at room temperature for $60 \mathrm{~min}$ at $\mathrm{pH} 4.2$. To this reaction mixture, $20 \mu \mathrm{L}$ of $1 \mathrm{mM}$ DTPA were added, and the solution was incubated at room temperature for $15 \mathrm{~min}$ to complex any free ${ }^{111}$ In ions with DTPA. The radiolabeling yield was determined by instant thin-layer chromatography with silica gel impregnated on glass fiber (ITLC; Gelman Sciences) developed with $10 \%$ ammonium acetate in water/methanol (1:1). The radioactivity peak areas were integrated with a Bioscan radiochromatogram scanner (Bioscan, Inc.). On ITLC, the radiolabeled antibody remains at the origin of application and ${ }^{111}$ In-DTPA moves with the solvent front. Radiolabeled antibody preparations were purified with a PD-10 size-exclusion column (GE Healthcare Bio-Sciences $\mathrm{AB}$ ) with phosphate-buffered saline (PBS) as the elution buffer. The radiochemical purity was assessed by high-performance liquid chromatography ([HPLC] Gilson) equipped with a size-exclusion TSK gel G3000SW $\mathrm{XL}_{\mathrm{X}}$ column $(7.8 \times 300 \mathrm{~mm}, 5 \mu \mathrm{m}$; TOSOH Bioscience, Japan; $0.067 \mathrm{M}$ sodium phosphate/0.1 M potassium chloride, $\mathrm{pH} 6.8 ; 1.0 \mathrm{~mL} / \mathrm{min}$ ), an ultraviolet monitor, and an online flow radioactivity detector (Bioscan, Inc.).

\section{Cell Culture}

A431, a human epidermoid carcinoma cell line that expresses the Lewis ${ }^{\mathrm{y}}$ antigen recognized by B3, was grown in RPMI 1640 medium supplemented with $10 \%$ fetal calf serum, $2 \mathrm{mM}$ L-glutamine, penicillin $(100 \mathrm{IU} / \mathrm{mL})$, and streptomycin $(100 \mu \mathrm{g} / \mathrm{mL})$ at $37^{\circ} \mathrm{C}$ in a humidified atmosphere with $5 \% \mathrm{CO}_{2}$. Cells were harvested with ethylenediaminetetraacetic acid (EDTA)-trypsin, washed with PBS, and resuspended in PBS with $1 \%$ bovine serum albumin for immunoreactivity determination or resuspended in PBS only for biodistribution studies.

\section{Cell-Binding Assay}

The cell-binding assay was reported previously (18). In brief, a constant concentration of ${ }^{111} \mathrm{In}-\mathrm{MX}-\mathrm{B} 3(5 \mathrm{ng}$ ) was incubated with $2 \times 10^{4}$ to $2 \times 10^{6} \mathrm{~A} 431$ cells for $2 \mathrm{~h}$ at $4^{\circ} \mathrm{C}$. Cell-bound radioactivity was separated by centrifugation and counted in a $\gamma$-counter. The percentage of maximum specific cell-bound radioactivity was used as the measure of immunoreactivity. 


\section{Tumor Model}

Animal experiments were performed under a protocol approved by the NIH Animal Care and Use Committee. Tumor xenografts were established by subcutaneous inoculation of $3 \times 10^{6}$ A431cells in $0.1 \mathrm{~mL}$ PBS into each flank of athymic mice (NCI-DCT).

\section{Pulsed-HIFU System}

The pulsed-HIFU exposures were performed using a custombuilt, image-guided HIFU system, modified from a Sonoblate 500 (Focus Surgery). The probe was composed of both a spheric, concave therapeutic transducer $(1 \mathrm{MHz} ; 5-\mathrm{cm}$ diameter, 4-cm focal length) and a collinear imaging transducer $(10 \mathrm{MHz}$; $8-\mathrm{mm}$ aperture). The therapeutic transducer's focal zone was in the shape of an elongated ellipsoid, with an axial length $(-3 \mathrm{~dB})$ of $7.2 \mathrm{~mm}$ and a radial diameter $(-3 \mathrm{~dB})$ of $1.38 \mathrm{~mm}$.

\section{Pulsed-HIFU Exposures}

Pulsed-HIFU exposures were performed as described previously (26). For all mice receiving pulsed-HIFU exposures, only 1 of 2 tumors was treated with HIFU. Mice were kept anesthetized with inhaled isoflurane $\left(2 \%\right.$ in $\left.\mathrm{O}_{2}, 1 \mathrm{~L} / \mathrm{h}\right)$ throughout the exposure process. Both tumors were covered with ultrasonic coupling gel. An individual mouse was secured in a holder, which was connected to a 3-dimensional stage, and then placed upright in a tank of degassed water $\left(37^{\circ} \mathrm{C}\right)$. The stage was used to position the tumor directly at the focal zone of the transducer using the graphic user interface of the pulsed-HIFU system. The beam was directed at the center of the tumor's depth (z-dimension). A rastering pattern in the $x$ - and $y$-plane was designated in a 2-dimensional grid, with a lateral $(x)$ and vertical (y) spacing of $2 \mathrm{~mm}$ between raster points. The following exposure parameters were used: total acoustic power (TAP), 20 or $40 \mathrm{~W}$; pulse repetition frequency, $1 \mathrm{~Hz}$; duty cycle, 5\% (50 ms "on" and $950 \mathrm{~ms}$ "off"). One hundred pulses were given at each raster point.

\section{Biodistribution Studies}

Pulsed-HIFU exposures were performed when tumors reached an approximate size of $0.5 \mathrm{~cm}^{3}$. At this size, a typical pulsedHIFU exposure lasted 8-15 min. Groups of 5 mice were injected intravenously with ${ }^{111} \mathrm{In}-\mathrm{MX}-\mathrm{B} 3(74 \mathrm{kBq} / 1.5 \mu \mathrm{g})$ in $0.2 \mathrm{~mL}$ of PBS, $\mathrm{pH} 7.2$, containing $1 \%$ bovine serum albumin. When animals received both pulsed-HIFU exposures and injections of ${ }^{111}$ In-MXB3, the exposures always preceded the injections. The animals were euthanized at $1,24,48$, and $120 \mathrm{~h}$ by $\mathrm{CO}_{2}$ inhalation and exsanguinated by cardiac puncture before dissection. Blood and various organs were excised and weighed, and their decaycorrected radioactivity counts were measured with a $\gamma$-counter (PerkinElmer Inc.). The percentage of injected dose per gram (\% ID/g) of the blood or each organ was calculated and normalized to a 20 -g mouse. The whole-body radioactivity count was obtained by adding the radioactivity of all organs to that of the carcass as measured by the $\gamma$-counter, and the radioactivity was expressed as the percentage of the injected dose (\%ID). Tumor-to-blood and tumor-to-tissue ratios $(\% \mathrm{ID} / \mathrm{g}$ in the HIFU-treated tumor divided by the $\% \mathrm{ID} / \mathrm{g}$ in normal tissue) were also determined. Timeactivity curves for ${ }^{111} \mathrm{In}-\mathrm{MX}-\mathrm{B} 3$ were generated from the mean $\% \mathrm{ID} / \mathrm{g}$ in both tumors. The area under the curve (AUC) $(\% \mathrm{ID} \times$ $\mathrm{h} / \mathrm{g}$ ) was then calculated using a trapezoid integration from 1 to $120 \mathrm{~h}(25)$.

\section{Imaging Studies}

Nuclear imaging of tumor-bearing mice was performed using an A-SPECT system (Gamma Medica Instruments) with a 2-mm pinhole collimator. Mice were injected intravenously with $11 \mathrm{MBq}$ (32 $\mu \mathrm{g})$ of ${ }^{111} \mathrm{In}-\mathrm{MX}-\mathrm{B} 3$ after the HIFU treatment. The animals were anesthetized with ketamine $(60 \mathrm{mg} / \mathrm{kg}) / \mathrm{xylazine}(10 \mathrm{mg} / \mathrm{kg})$ immediately before imaging. Static imaging was acquired for 40,000 counts at 1,24 , and $120 \mathrm{~h}$ after injection.

\section{Histology}

Both exposed and unexposed tumors were collected for histological analysis, as well as skin, bone, and thigh muscle adjacent to the exposed tumors. Immediately after exposures, animals $(n=$ 3 ) were euthanized. Tissues were removed, placed in formalin for $24 \mathrm{~h}$ at $4^{\circ} \mathrm{C}$, embedded in paraffin, sectioned, and stained with hematoxylin and eosin. Samples were viewed at $200 \times$ magnification with an Axioplan2 imaging microscope (Zeiss) with an AxioCam digital camera, using AxioVS40 4.4 software.

\section{RESULTS}

\section{Radiolabeling and Cell Binding}

The ${ }^{111}$ In-labeling yield of MX-B3 was $>92 \%$ based on the ITLC analysis. The radiochemical purity of the PD-10purified ${ }^{111}$ In-MX-B3 was $100 \%$ on the basis of the ITLC analysis, but the size-exclusion HPLC profile of the purified ${ }^{111}$ In-MX-B3 showed 2 antibody components: $93 \%$ of the radioactivity was associated with monomeric B3 (retention time, $9.3 \mathrm{~min}$ ) and the remaining radioactivity was associated with a broader peak (retention time, $8.0 \mathrm{~min}$ ), presumably representing a dimeric form of B3. We used ${ }^{111} \mathrm{In}-\mathrm{MX}-\mathrm{B} 3$ with an immunoreactivity of $70 \%$ and a specific activity of 8-12 $\mu \mathrm{Ci} / \mu \mathrm{g}$ for animal studies.

\section{Effect of HIFU on Uptake of ${ }^{111}$ In-MX-B3 in Tumors and Organs}

The effect of the HIFU exposure on tumor uptake was investigated with a TAP of 20 or $40 \mathrm{~W}$. At $20 \mathrm{~W}$, there was no difference in tumor uptake between the HIFU and the control tumors when the tumor uptake was investigated by nuclear imaging at 1,24 , and $120 \mathrm{~h}$ after injection. In contrast, the HIFU exposures at $40 \mathrm{~W}$ resulted in earlier and more intense visualization of tumor than the control without the HIFU (Fig. 1). Therefore, for the remainder of the study, a TAP of $40 \mathrm{~W}$ was used to quantitatively investigate the effect of HIFU exposure on tumor uptake. The biodistribution of ${ }^{111}$ In-MX-B3 was studied at 1, 24, 48, and $120 \mathrm{~h}$ after HIFU exposure. The results of the experiments are summarized in Figure 2. ${ }^{111}$ In-MX-B3 decreased gradually from blood, whereas the radioactivity increased in tumors and major organs over time. The highest level $(37.55 \pm 16.37 \% \mathrm{ID} / \mathrm{g})$ of ${ }^{111}$ In-MX-B3 in the pulsed-HIFU-exposed tumors was observed at $24 \mathrm{~h}$, whereas the highest tumor uptake (24.99 \pm $2.40 \% \mathrm{ID} / \mathrm{g}$ ) in the control tumors without the pulsed-HIFU exposure was observed at $48 \mathrm{~h}$. The uptake in tumors with the pulsed-HIFU exposure was $>2$ times higher than that in the control tumors at $1 \mathrm{~h}(2.57 ; P<0.05)$ and $24 \mathrm{~h}(2.13 ; P<$ 0.02 ), but the uptake in the pulsed-HIFU-exposed tumors 
A

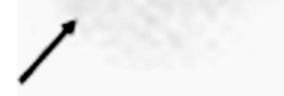

$1 \mathrm{~h}$

B
$1 \mathrm{~h}$

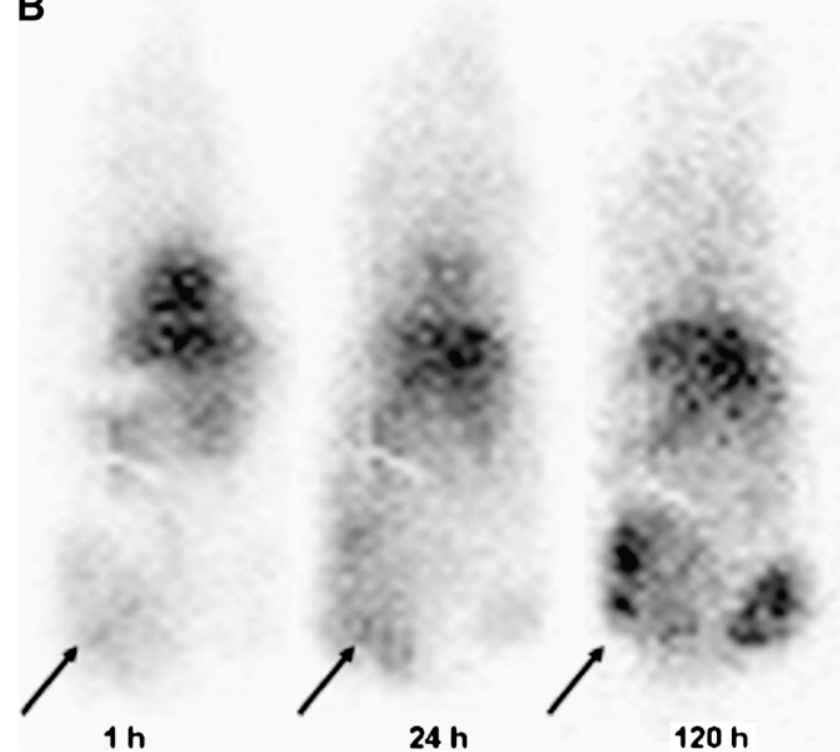

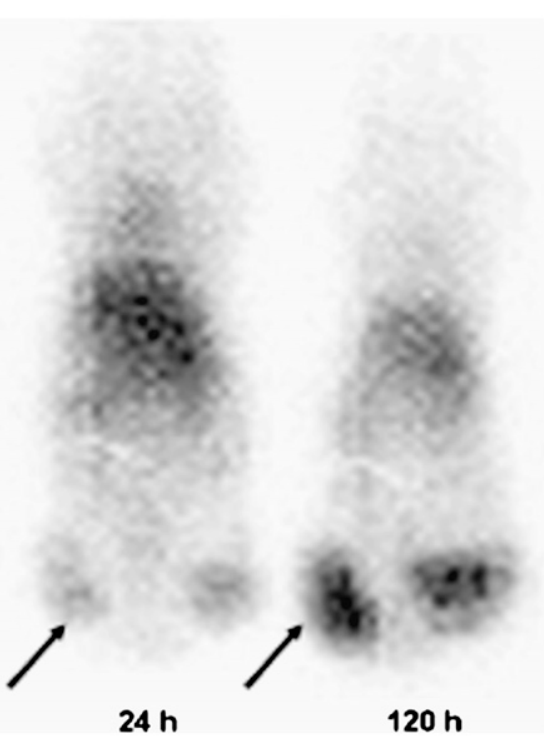

$24 \mathrm{~h}$

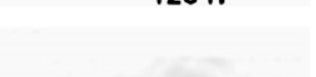

FIGURE 1. Images of A431 tumor-bearing nude mice receiving intravenous ${ }^{111} \mathrm{In}-\mathrm{MX}-\mathrm{B} 3$. Tumors were exposed to pulsed-HIFU with 2 exposure parameters: TAP of $20 \mathrm{~W}(\mathrm{~A})$ and TAP of $40 \mathrm{~W}(\mathrm{~B})$; pulse repetition frequency, $1 \mathrm{~Hz}$; duty cycle, $5 \%$ (50 ms on and $950 \mathrm{~ms}$ off). One hundred pulses were given at each raster point. Within $10 \mathrm{~min}$, mice were injected intravenously with $11 \mathrm{MBq}(32 \mu \mathrm{g})$ of ${ }^{111} \mathrm{In}-\mathrm{MX}-\mathrm{B} 3$. Static imaging was acquired for 40,000 counts at 1,24 , and $120 \mathrm{~h}$ after injection and immediate anesthetization with ketamine $(60 \mathrm{mg} / \mathrm{kg}) / x y$ lazine $(10 \mathrm{mg} / \mathrm{kg})$. Pulsed-HIFU-exposed tumors are indicated by arrows. Animals pulsed at $40 \mathrm{~W}$ had earlier and higher uptake than those treated at $20 \mathrm{~W}$. The difference between treated and nontreated tumors at $40 \mathrm{~W}$ was equalized by $120 \mathrm{~h}$.

decreased almost to the level of the control tumors at $120 \mathrm{~h}$ (Fig. 2). The AUC analysis for the tumor uptake and retention curves of the HIFU-exposed tumors and the control tumors resulted in 3,433 $\pm 886(\% \mathrm{ID} \times \mathrm{h} / \mathrm{g})$ and $2,521 \pm 352(\% \mathrm{ID} \times$ $\mathrm{h} / \mathrm{g})$, respectively, for a 120 -h period $(P<0.04)$. Tumor-toblood and tumor-to-organ ratios increased over time for the

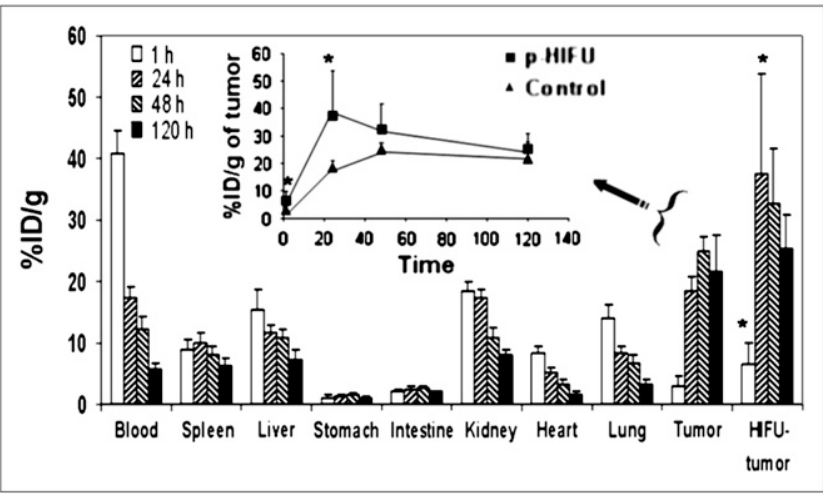

FIGURE 2. Biodistribution (\%ID/g; $n=4-6$ ) of ${ }^{111} \mathrm{In}-\mathrm{MX}-\mathrm{B} 3$ in A431 tumor-bearing nude mice. One tumor was treated with pulsed-HIFU at $40 \mathrm{~W}$ and the contralateral tumor was used as a control. Each mouse received $74 \mathrm{kBq} / 1.5 \mu \mathrm{g}$ of ${ }^{111} \mathrm{In}-\mathrm{MX}-\mathrm{B} 3$ and uptake was measured at 1, 24, 48, and $120 \mathrm{~h}$ after injection. Data are shown as \%ID/g of tissue and were normalized to a $20-\mathrm{g}$ mouse (mean $\pm \mathrm{SD}$ ). Insertion is uptake and retention of ${ }^{111}$ In-MX-B3 in A431 tumors. Pulsed-HIFU ( $p$-HIFU) exposure shortened peak tumor uptake time and increased peak tumor uptake value compared with that of untreated control tumors. AUC calculation for 120 -h period resulted in a $1.4 \times$ higher value for pulsed-HIFU-exposed tumors than that for control tumors. ${ }^{\star} P<0.05$.

tumors with and without pulsed-HIFU exposure, indicating preferential retention of ${ }^{111} \mathrm{In}-\mathrm{MX}-\mathrm{B} 3$ in tumors (Fig. 3). The imaging studies (Fig. 1) also substantiated the results from the biodistribution studies showing earlier and greater uptake in HIFU-exposed tumors at 1 and $24 \mathrm{~h}$ with equalization to the level of the control tumor at $120 \mathrm{~h}$.

\section{Effect of HIFU on Accumulation of ${ }^{111}$ In-MX-B3 in Surrounding Tissues}

To assess the effect of the pulsed-HIFU exposure on the antibody accumulation in the tissues that were in close proximity to the exposed tumor, we studied the accumulation of the antibody in the muscle and bone under the exposed

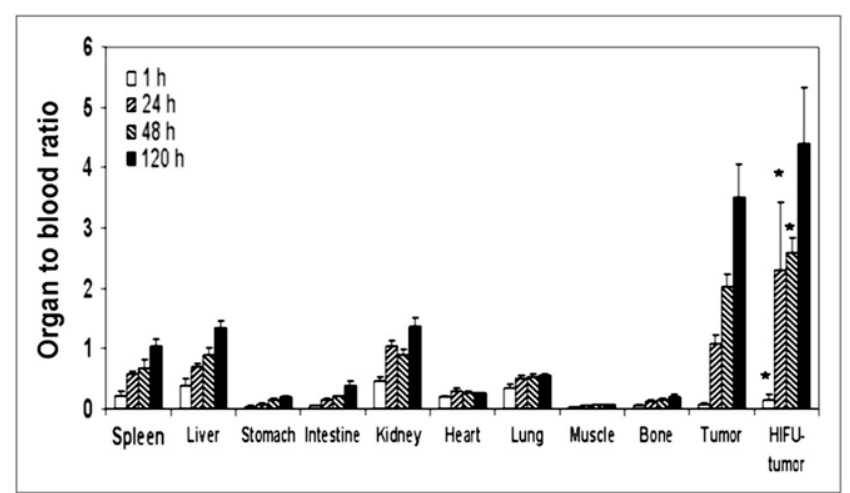

FIGURE 3. Organ-to-blood ratios of ${ }^{111} \mathrm{In}-\mathrm{MX}-\mathrm{B} 3$ in nude mice with A431 tumors. Ratios were obtained by dividing uptake $(\% \mathrm{ID} / \mathrm{g})$ in organs by that $(\% \mathrm{ID} / \mathrm{g})$ in blood. Tumor-toblood ratios increased more than organ-to-blood ratios over time, indicating preferential retention in tumors. Data are expressed as mean \pm SD. ${ }^{\star} P<0.05$. 
tumor and in skin on top of the exposed tumor, as well as inside the thigh of the exposed limb. The results are summarized in Figure 4. The highest relative effect of HIFU on the accumulation of antibodies was observed in muscle under the treated tumor. Accumulation in the muscle peaked at $24 \mathrm{~h}$ after treatment, reaching a nearly 10-fold increase compared with that of the control side. However, the absolute increase in the HIFU-exposed muscle was relatively low as the basal level of the antibody accumulation in the muscle tissue was only $5 \%$ of that in the tumor. Histological analysis of the skin, tumor, muscle, and bone in both the treated and untreated flanks did not reveal any structural damage caused by HIFU treatment (Fig. 5).

\section{DISCUSSION}

It was previously demonstrated that pulsed-HIFU exposures in solid tumors could enhance the delivery of various types of agents (small molecules, nanoparticles, plasmid DNA) in murine models. As a result of this enhancement, an increase in the therapeutic effects of these agents was achieved (26). The purpose of the current study was to investigate if pulsed-HIFU exposures could enhance the delivery of an mAb, ${ }^{111} \mathrm{In}-\mathrm{MX}-\mathrm{B} 3$, to a solid human epidermoid tumor in a murine model. The tumor uptake and retention of ${ }^{111}$ In-MX-B3 in the control tumors not receiving the pulsedHIFU exposure was similar to that reported previously $(24,25)$. In contrast, the pulsed-HIFU exposure increased the tumor peak uptake value $(37.55 \pm 16.37$ vs. $24.99 \pm 2.40$ $\% \mathrm{ID} / \mathrm{g}$ for control tumor) and shortened the peak tumor uptake time ( 24 vs. 48 h) compared with the control tumor. Ongoing mechanistic studies on the delivery enhancement by pulsed-HIFU in solid tumors would seem to preclude heat generation or acoustic cavitation (27), which have been shown to facilitate the delivery of drugs. Instead, it has been proposed (27) that pulsed-HIFU generates acoustic radiation forces that occur due to absorption of energy in the focal

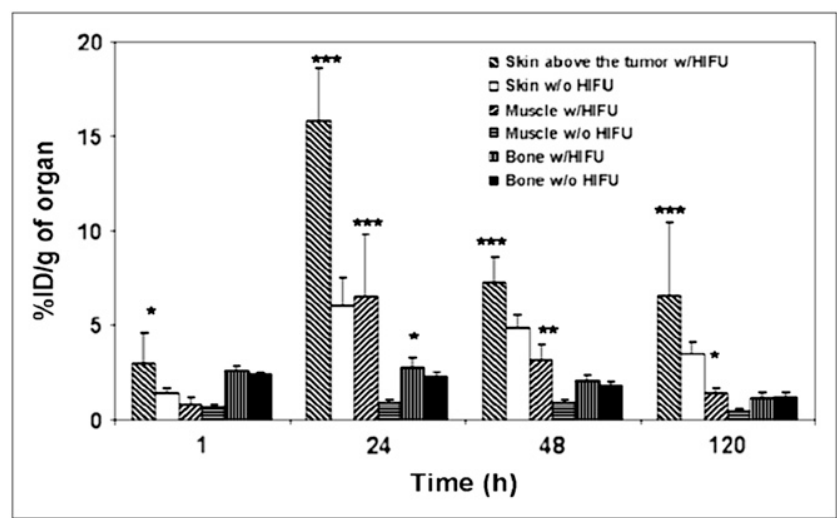

FIGURE 4. Effect of pulsed-HIFU exposure to tumor on uptake (\%ID/g, $n=4 \sim 6)$ of ${ }^{111}$ In-MX-B3 in muscle, skin, and bone near tumor (mean $\pm \mathrm{SD}$ ). ${ }^{*} 0.01<P<0.05 ;{ }^{* \star} 0.001<P<$ $0.01 ;{ }^{\star \star \star} P<0.001$. Significant differences were observed between skin, muscle, and bone in HIFU-treated and nonHIFU-treated side. w/ = with; w/o = without.


FIGURE 5. Hematoxylin-eosin staining of control (left) and pulsed-HIFU-treated (right) tissues. (A and B) Skin. (C and D) Tumor. ( $E$ and $F)$ Muscle. ( $G$ and $H$ ) Bone. (Hematoxylin-eosin, $\times 200$; bar $=100 \mu \mathrm{m}$.) No visual difference in histology was evident between tumor or adjacent tissue of HIFU-treated compared with untreated side.

zone, thereby producing local displacements in the tissues in and around the focal region. Nonuniform displacement between adjacent regions of tissue can induce shear forces, by which the resulting strain acts on the weakest structural elements in the tissue; junctions, and interfaces between individual cells and factors in the extracellular matrix (ECM). Widening of intercellular gaps, for example, due to both focused and unfocused ultrasound exposures, has been shown previously $(28,29)$. Results of the present study show that exposures at $20 \mathrm{~W}$ do not produce enhanced delivery of the mAb, whereas at $40 \mathrm{~W}$ the delivery was enhanced. Increased delivery of nanoparticles in murine tumors, using the same exposure has been correlated with increasing power, whereby displacements induced in the tissue were also proportionally increased (27). 
The HIFU effect found on antibody uptake is consistent with a hypothesis that the improved extravasation of the radiolabeled antibody was primarily induced by the lowering of high interstitial fluid pressure (IFP) by the HIFU exposure. Because the mAb $\mathrm{B} 3$ in the present study was able to penetrate into the control tumor tissue on its own, it is believed that potential widening of the intercellular space (endothelial junction) between endothelial cells in the tumor vasculature may have been less important than effects produced in the parenchyma. High IFP is known to reduce the driving force for extravasation in tumors despite large gaps in the endothelium (30) and severely limits the delivery of drugs (26). On the other hand, widening of intercellular gaps between parenchymal cells and disruption of fibrillar collagen may have led to improved hydraulic conductivity, redistribution of fluid, and, ultimately, lower IFP for improved extravasation. The opening up of intercellular spaces in tissues exposed to ultrasound has been shown to improve nanoparticle transport in the interstitium. Disruption of fibrillar collagen in the ECM was found to enhance interstitial transport (31) and the distribution of therapeutics (32).

The pulsed-HIFU approach may provide some advantage over 2 other approaches currently under investigation to improve tumor targeting: the use of antibody fragments (14-16) and 2- or 3-step pretargeting methods to improve tumor-targeting kinetics (17-19). In contrast to radiolabeled fragments that can improve the peak tumor uptake time at the expense of lowering peak uptake values due to rapid renal excretion, pulsed-HIFU exposure improved both tumor uptake kinetics and the peak tumor uptake value. Compared with pretargeting approaches involving multiple injections of multiple components-including an antibody conjugate, a clearance agent, and a radiolabel - the use of pulsed-HIFU to enhance delivery involves the injection of a single agent, radiolabeled antibody.

Tumor uptake in this study reached a maximum level at $24 \mathrm{~h}$, with the pulsed-HIFU peak value being twice as great as that without the pulsed-HIFU treatment, but decreased to the level of the control tumor at $120 \mathrm{~h}$. The radioactivity ratio of the HIFU tumor to control tumor was 2.6, 2.1, 1.3, and 1.2 at 1,24, 48, and $120 \mathrm{~h}$, respectively. On the basis of our findings, the HIFU-exposed tumors did not have visible histological differences compared with the untreated controls. These results are consistent with previous studies using the same exposures in murine tumors, where no damaging effects in the tissues were observed $(26,33)$. Nor was there inhibition of tumor growth rates compared with the untreated controls (26). The tumor uptake kinetics (Fig. 2) suggest that a substantial portion of the additional antibody in the HIFU-exposed tumors might not have bound to antigens on tumor cells and that this excess unbound antibody or antibody bound to soluble antigen in extracellular fluid might have washed out of the tumors over time. It is also possible that the pulsed-HIFU exposure affected antigen expression, modulation, shedding, and antibody-binding affinity of Lewis ${ }^{y}$ antigen, and these may have limited the level of antibody binding to the HIFU-exposed tumor to the level of the control tumor uptake at $120 \mathrm{~h}$. However, the effect of pulsed-HIFU on tumor cell antigens is unknown and must be investigated. Nevertheless, the enhancement in tumor uptake kinetics and tumor uptake value by pulsedHIFU is encouraging in that $\alpha$ - and $\beta$-particles in the extracellular fluid in the vicinity of tumor cells would effectively irradiate tumor cells because the distance between the capillary and tumor cells is generally in the range of $0-100 \mu \mathrm{m}$, whereas the radiation track distance in tissues is $\sim 60 \mu \mathrm{m}$ for $\alpha$-emitters and $1-5 \mathrm{~mm}$ for $\beta$-emitters (34-36).

Calculating the AUC for the 120-h period of the study indicated that a single pulsed-HIFU treatment could increase the radiation exposure dose of tumors by $36 \%$ compared with untreated control tumors. In light of the fact that, in tumorbearing nude mouse models, solid tumors respond-albeit only a small percentage - to monotherapy using ${ }^{90}$ Y-labeled $\mathrm{mAb}$ at the maximum tolerated dose (MTD), whereas the cure rate increases synergistically at well below the MTD when ${ }^{90} \mathrm{Y}$-labeled $\mathrm{mAb}$ is combined with taxol (37-39), it is more likely that the $36 \%$ increase in cumulative radioactivity delivered to tumor is significant enough to provide an enhanced synergistic effect when pulsed-HIFU treatment is added to a combination therapy of ${ }^{90} \mathrm{Y}$-labeled mAb with taxol. We believe that pulsed-HIFU treatment might potentially provide complete response when added to a combined therapy of ${ }^{90} \mathrm{Y}-\mathrm{mAb}$ and taxol at doses much below MDT, thereby increasing the therapeutic index.

The biodistribution of ${ }^{111} \mathrm{In}-\mathrm{MX}-\mathrm{B} 3$ in mice with pulsedHIFU-exposed tumors was similar to that reported previously for mice without pulsed-HIFU exposure $(24,25)$; the uptake in blood, lung, and bone was almost identical in these studies. However, uptake in other organs, such as liver, spleen, and kidney, was slightly higher in this study, perhaps because the ${ }^{111}$ In-MX-B3 prepared for this study contained a small fraction (7\%) of a dimeric or higher molecular form of B3 that was taken up by reticular endothelial cells in the liver and spleen or catabolized into smaller antibody fragments that were then taken up by the kidneys, thereby resulting in a slight increased uptake in these organs. Nevertheless, the lack of increased radioactivity in blood or distant bone indicates that HIFU should not cause any unexpected toxicity to bone marrow. For the future radioimmunotherapy study with ${ }^{90} \mathrm{Y}-\mathrm{MX}-\mathrm{B} 3$, we will remove the dimer and oligomers of $\mathrm{B} 3$ by size-exclusion HPLC and use only a monomeric form of B3.

The main limitation of this study is the relatively small size of the tumors, which were similar in size to the focal zone of the HIFU beam produced by our device. As a result, energy deposition in the adjacent skin and muscle was high enough to produce delivery enhancement, evident by the increased levels of antibodies detected in those tissues compared with the control side (Fig. 4). Acoustic radiation forces, and consequent displacements generated in the tissue, are typically higher at tissue interfaces (e.g., 
skin/tumor and tumor/muscle), where increased reflection of ultrasound waves occurs (40). The highest relative effect of HIFU on the accumulation of the antibody was observed in muscle under the treated tumor. Accumulation in the muscle peaked at $24 \mathrm{~h}$ after treatment, reaching a nearly $10-$ fold increase compared with the control side. However, the absolute increase in the HIFU-exposed muscle was relatively low as the basal level of the antibody accumulation in the muscle tissue was only $5 \%$ of that in the tumor. We investigated only the HIFU effect on the delivery to skin and muscle surrounding the HIFU-exposed tumors because the tumors were in the flank away from liver, spleen, and kidney and the focal zone of the HIFU beam was similar in size to the tumor size. This phenomenon of the enhanced uptake in normal tissue would be minimized when treating larger tumors in human patients because, in those cases, the focal zone could be placed sufficiently distant from adjacent, nontumor tissue. For instance, when using continuous HIFU exposures for ablation, tumors can be treated very accurately with negligible effects on surrounding healthy tissue (20).

\section{CONCLUSION}

We have demonstrated that noninvasive and nondestructive pretreatment with pulsed-HIFU significantly enhances the delivery of ${ }^{111} \mathrm{In}-\mathrm{MX}-\mathrm{B} 3$ in human epidermoid tumors xenografted in nude mice, with more rapid uptake and higher overall levels of the mAb being achieved in targeted tumor. The results of this pilot study warrant further evaluation of other treatment regimens, such as repeated HIFU exposures that could potentially result in even greater delivery enhancement of antibodies labeled with cytotoxic radioisotopes to solid tumors and pulsed-HIFU exposure in addition to a combined therapy of ${ }^{90} \mathrm{Y}-\mathrm{B} 3$ and taxol to further enhance the synergistic effect.

\section{ACKNOWLEDGMENTS}

The authors thank Dr. Clara Chen for critical review and Eleanor Chuang for editorial assistance of the manuscript.

\section{REFERENCES}

1. Green MC, Murray JL, Hortobagyi GN. Monoclonal antibody therapy for solid tumors. Cancer Treat Rev. 2000;26:269-286.

2. Hainsworth JD. Monoclonal antibody therapy in lymphoid malignancies. Oncologist. 2000;5:376-384.

3. Tabernero J. The role of VEGF and EGFR inhibition: implications for combining anti-VEGF and anti-EGFR agents. Mol Cancer Res. 2007;5:203-220.

4. Cilley JC, Barfi K, Benson AB III, Mulcahy MF. Bevacizumab in the treatment of colorectal cancer. Expert Opin Biol Ther. 2007;7:739-749.

5. Kaminski MS, Zelenetz AD, Press OW, et al. Pivotal study of I-131 tositumomab for chemotherapy-refractory low-grade or transformed low-grade B-cell nonHodgkin's lymphomas. J Clin Oncol. 2001;19:3918-3928.

6. Witzig TE, Gordon LI, Cabanillas F, et al. Randomized controlled trial of yttrium90-labeled ibritumomab tiuxetan radioimmunotherapy versus rituximab immunotherapy for patients with relapsed or refractory low-grade, follicular, or transformed B-cell non-Hodgkin's lymphoma. J Clin Oncol. 2002;20:2453-2463.
7. Waldmann TA, White JD, Carrasquillo JA, et al. Radioimmunotherapy of interleukin-2R alpha-expressing adult T-cell leukemia with yttrium-90-labeled anti-Tac. Blood. 1995;86:4063-4075.

8. DeNardo GL, Sysko VV, DeNardo SJ. Cure of incurable lymphoma. Int J Radiat Oncol Biol Phys. 2006;66(2 suppl):S46-S56.

9. Yu B, Carrasquillo J, Milenic D, et al. Phase I trial of iodine 131-labeled COL-1 in patients with gastrointestinal malignancies: influence of serum carcinoembryonic antigen and tumor bulk on pharmacokinetics. J Clin Oncol. 1996;14: 1798-1809.

10. Pai-Scherf LH, Carrasquillo JA, Paik C, et al. Imaging and phase I study of ${ }^{111} \mathrm{In}-$ and ${ }^{90}$ Y-labeled anti-Lewis ${ }^{\mathrm{Y}}$ monoclonal antibody B3. Clin Cancer Res. 2000;6: 1720-1730.

11. Christiansen J, Rajasekaran AK. Biological impediments to monoclonal antibody-based cancer immunotherapy. Mol Cancer Ther. 2004;3:1493-1501.

12. Jain M, Venkatraman G, Batra SK. Optimization of radioimmunotherapy of solid tumors: biological impediments and their modulation. Clin Cancer Res. 2007;13: 1374-1382.

13. Saga T, Neumann RD, Heya T, et al. Targeting cancer micrometastases with monoclonal antibodies: a binding-site barrier. Proc Natl Acad Sci USA. 1995; 92:8999-9003.

14. Yokota T, Milenic DE, Whitlow M, Schlom J. Rapid tumor penetration of a single-chain Fv and comparison with other immunoglobulin forms. Cancer Res. 1992;52:3402-3408.

15. Choi CW, Lang L, Lee JT, et al. Biodistribution of ${ }^{18} \mathrm{~F}$ - and ${ }^{125} \mathrm{I}$-labeled anti-Tac disulfide-stabilized Fv fragments in nude mice with interleukin 2 alpha receptorpositive tumor xenografts. Cancer Res. 1995;55:5323-5329.

16. Adams GP, Tai MS, McCartney JE, et al. Avidity-mediated enhancement of in vivo tumor targeting by single-chain Fv dimers. Clin Cancer Res. 2006;12:15991605 .

17. Axworthy DB, Reno JM, Hylarides MD, et al. Cure of human carcinoma xenografts by a single dose of pretargeted yttrium- 90 with negligible toxicity. Proc Natl Acad Sci USA. 2000;97:1802-1807.

18. Yao Z, Zhang M, Axworthy DB, et al. Radioimmunotherapy of A431 xenografted mice with pretargeted $\mathrm{B} 3$ antibody-streptavidin and ${ }^{90} \mathrm{Y}$-labeled 1,4,7,10-tetraazacyclododecane-N, $\mathrm{N}^{\prime}, \mathrm{N}^{\prime \prime}, \mathrm{N}^{\prime \prime \prime}$-tetraacetic acid (DOTA)-biotin. Cancer Res. 2002;62:5755-5760.

19. Goldenberg DM, Sharkey RM, Paganelli G, Barbet J, Chatal JF. Antibody pretargeting advances cancer radioimmunodetection and radioimmunotherapy. J Clin Oncol. 2006;24:823-834.

20. Kennedy JE. High-intensity focused ultrasound in the treatment of solid tumours. Nat Rev Cancer. 2005;5:321-327.

21. Frenkel V, Li KC. Potential role of pulsed-high intensity focused ultrasound in gene therapy. Future Oncol. 2006;2:111-119.

22. Kinoshita M, McDannold N, Jolesz FA, Hynynen K. Noninvasive localized delivery of Herceptin to the mouse brain by MRI-guided focused ultrasoundinduced blood-brain barrier disruption. Proc Natl Acad Sci USA. 2006;103: 11719-11723.

23. Pastan I, Lovelace ET, Gallo MG, Rutherford AV, Magnani JL, Willingham MC. Characterization of monoclonal antibodies B1 and B3 that react with mucinous adenocarcinomas. Cancer Res. 1991;51:3781-3787.

24. Camera L, Kinuya S, Garmestani K, et al. Evaluation of a new DTPA-derivative chelator: comparative biodistribution and imaging studies of ${ }^{111} \mathrm{In}$-labeled B3 monoclonal antibody in athymic mice bearing human epidermoid carcinoma xenografts. Nucl Med Biol. 1993;20:955-962.

25. Camera L, Kinuya S, Garmestani K, et al. Comparative biodistribution of indium- and yttrium-labeled B3 monoclonal antibody conjugated to either 2(p-SCN-Bz)-6-methyl-DTPA (1B4M-DTPA) or 2-(p-SCN-Bz)-1,4,7,10-tetraazacyclododecane tetraacetic acid (2B-DOTA). Eur J Nucl Med. 1994;21:640-646.

26. Frenkel V, Etherington A, Greene M, et al. Delivery of liposomal doxorubicin (Doxil) in a breast cancer tumor model: investigation of potential enhancement by pulsed-high intensity focused ultrasound exposure. Acad Radiol. 2006;13: 469-479.

27. Frenkel V, Deng C, O'Neill B, et al. Pulsed-high intensity focused ultrasound (HIFU) exposures for enhanced delivery of therapeutics: mechanisms and applications. Paper presented at: The 5th International Symposium on Therapeutic Ultrasound; October 27-29, 2005; Boston, MA.

28. Mesiwala AH, Farrell L, Wenzel H, et al. High-intensity focused ultrasound selectively disrupts the blood-brain barrier in vivo. Ultrasound Med Biol. 2002; 28:389-400.

29. Frenkel V, Kimmel E, Iger Y. Ultrasound-induced intercellular space widening in fish epidermis. Ultrasound Med Biol. 2000;26:473-480.

30. Boucher Y, Baxter LT, Jain RK. Interstitial pressure gradients in tissue-isolated and subcutaneous tumors: implications for therapy. Cancer Res. 1990;50: $4478-4484$. 
31. Netti PA, Berk DA, Swartz MA, Grodzinsky AJ, Jain RK. Role of extracellular matrix assembly in interstitial transport in solid tumors. Cancer Res. 2000;60: 2497-2503.

32. McKee TD, Grandi P, Mok W, et al. Degradation of fibrillar collagen in a human melanoma xenograft improves the efficacy of an oncolytic herpes simplex virus vector. Cancer Res. 2006;66:2509-2513.

33. Dittmar KM, Xie J, Hunter F, et al. Pulsed high-intensity focused ultrasound enhances systemic administration of naked DNA in squamous cell carcinoma model: initial experience. Radiology. 2005;235:541-546.

34. Milenic DE, Brady ED, Brechbiel MW. Antibody-targeted radiation cancer therapy. Nat Rev Drug Discov. 2004;3:488-499.

35. Couturier O, Supiot S, Degraef-Mougin M, et al. Cancer radioimmunotherapy with alpha-emitting nuclides. Eur J Nucl Med Mol Imaging. 2005;32: 601-614.
36. Back $\mathrm{T}$, Andersson $\mathrm{H}$, Divgi $\mathrm{CR}$, et al. ${ }^{211} \mathrm{At}$ radioimmunotherapy of subcutaneous human ovarian cancer xenografts: evaluation of relative biologic effectiveness of an alpha-emitter in vivo. J Nucl Med. 2005;46:2061-2067.

37. DeNardo SJ, Kukis DL, Kroger LA, et al. Synergy of taxol and radioimmunotherapy with yttrium-90-labeled chimeric L6 antibody: efficacy and toxicity in breast cancer xenografts. Proc Natl Acad Sci USA. 1997;94:4000-4004.

38. O'Donnell RT, DeNardo SJ, Miers LA, et al. Combined modality radioimmunotherapy for human prostate cancer xenografts with taxanes and yttrium 90-DOTA-peptide-ChL6. Prostate. 2002;50:27-37.

39. Masters GR, Berger MA, Albone EF. Synergistic effects of combined therapy using paclitaxel and $\left[{ }^{90} \mathrm{Y}-\mathrm{DOTA}\right] 776.1$ on growth of OVCAR-3 ovarian carcinoma xenografts. Gynecol Oncol. 2006;102:462-467.

40. Simonin J. On the mechanisms of in vitro and in vivo phonophoresis. J Control Release. 1995;33:125-141. 